\title{
Fasciola Hepatica Antioxidant System: Secretory Excretory System Proteins
}

\author{
Mara E Salazar Calderon ${ }^{1 *}$ and Rosa A Deschamps Lago ${ }^{2}$ \\ ${ }^{1}$ Facultad de Medicina Veterinaria y Zootecnia, Universidad Veracruzana, Mexico
}

${ }^{2}$ Facultad de Bioanalisis, Universidad Veracruzana, Mexico

*Corresponding author: Mara E Salazar Calderon, Facultad de Medicina Veterinaria y Zootecnia, Universidad Veracruzana, Mexico

\begin{abstract}
Fasciola hepatica is a trematode parasite with life cycle complex and as an intermediary it uses different species of snails, the most important is Lymnea truncatula. The definitive hosts being mainly ruminant mammals such as cows, sheep and even humans. The disease they produce is called fasciolosis and is more likely to find in warm to temperate climates with high humidity. It is an important parasitic problem in domestic animals and even in humans. This parasite lives in the bile ducts of several mammals. In order to survive in that environment, the parasite must survive to reactive oxygen species (ROS) of the host and those of its own metabolism. Here we review 3 antioxidant proteins of the parasite secretory excretory system and explain its possible mechanism of action. These proteins are: Thioredoxin peroxidase (TPx), Thioredoxin (TRX) and Thioredoxin glutathione reductase, considered a "general disulfide reductase". The antioxidant detoxification system of the parasite is thus fully described.
\end{abstract}

Keywords: Fasciola hepatica; Antioxidant proteins; Secretory excretory system

\section{Introduction}

Fasciola hepatica is a hermaphrodite trematode parasite belonging to the platyhelminths', which in its adult form is flattened, lanceolate, brown and measures approximately $3 \times 1.5 \mathrm{~cm}$. It has a conical structure in the front end where it is called suction mouth oral and it has a ventral cup-shaped suction cup surrounded by muscle mass that allows it to adhere to the host (Figure 1). Its life cycle is complex and as an intermediary it uses different species of snails, the most important is Lymnea truncatula, the definitive hosts being mainly ruminant mammals such as cows, sheep and humans (Figure 2). The adult form of the parasite produces 3 to 5 thousand eggs per day which leave in the feces of the definitive host and develop at temperatures of 10 to 30 degrees Celsius in an aqueous environment. They hatch causing larvae called miracidia that look for the intermediate host within which they will go through the phases of sporocysts, redid mother, redid daughter and cercariae. The cercarias leave the intermediaries and encyst in plants as metacercarias waiting to be ingested by who will be their definitive host. The metacercarias are very resistant and can survive up to a year before entering the final host. Inside the definitive host they lodge in the bile ducts. The disease they produce is called fasciolosis and is more likely to find in warm and temperate climates with high humidity. It is an important parasitic problem in domestic animals and humans. They cause inflammation of the bile ducts and fibrosis, hypoalbuminemia, anemia and alteration of certain liver enzymes. Although the parasite lives in an anaerobic environment, oxygen is used for some metabolic processes, such as egg production, which generates many oxidizing molecules. Parasites to prevent damage by these oxidants, both those of their metabolism and those of the host organism's metabolism, have developed a battery of antioxidant defenses that include enzymes that break down oxides and super oxides [1]. While more levels of defense possess a parasite, greater will be its survival within the host tissues. Helminth parasites in general have at least one of the 3 main antioxidant enzymes that are: superoxide dismutase, catalase and glutathione-dependent enzymes. In Fasciola no catalase has been found and it has low glutathione peroxidase activity [2], so it has other antioxidant enzymes. Fasciola hepatica has the following antioxidant enzymes and proteins, all present in the components of the excretory secretory extract which are part of a parasite detoxification system that allows its survival within the host $[3,4]$. Thioredoxin peroxidase (TPx), is a protein between 26 and $28 \mathrm{kDa}$ which forms dimers and tetramers due to a cysteine residue conserved in position 47 that forms disulfide bridges and is possibly the primary site responsible for oxidation. 


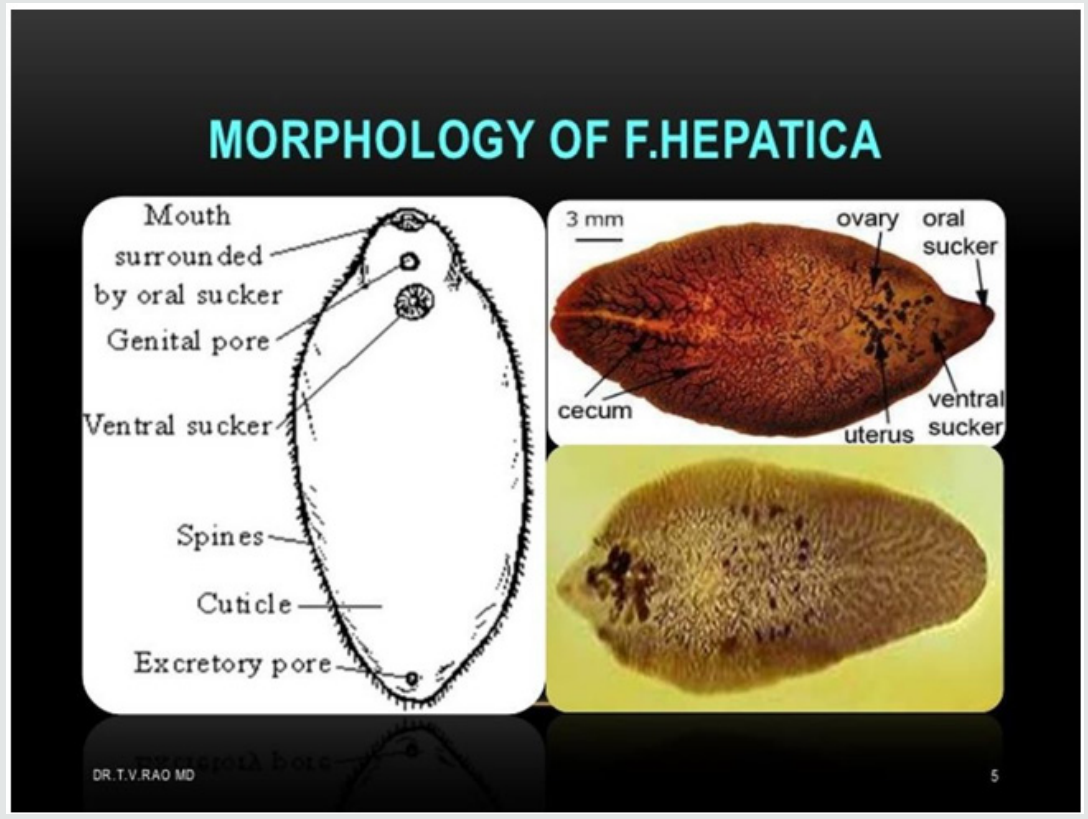

Figure 1: Morphology.

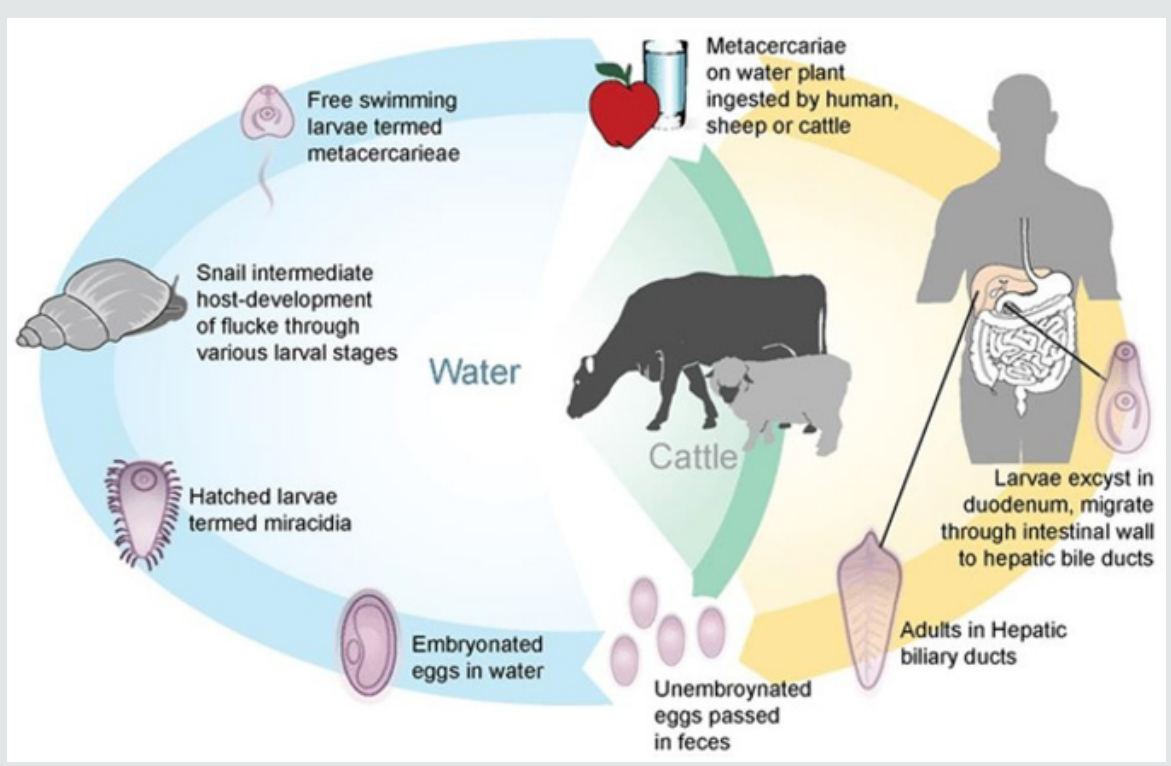

Figure 2: Water Planet management life cycle.

This protein has a protective activity against the inactivation of various enzymes by oxidation systems, but it is different from other TPxs from other parasites because in fasciola it works both in the presence of thiol and ascorbate groups, a relevant functional difference [5]. Another relevant fact and different from the other similar proteins of other parasites is that fasciola TPx has an extracellular location extending its protection against antioxidants to enzymes outside the parasite. The TPx mechanism could intervene in processes of protection of the inactivation of some membrane enzymes or exocellular parasite enzymes, making it possible to survive the host defense mechanisms [6,7]. Thioredoxin (TRX), representative protein of a group of widely distributed proteins that have dithiol-disulfide-oxidoreductase activity, its molecular mass is $12 \mathrm{kDa}$. Participates in important processes of metabolism and homeostasis. In the presence of TRX, the TPx protein protects enzymes more effectively against oxidation systems that employ DTT and / or ascorbate [6]. It is able to catalyze in vitro renaturation of both denatured insulin and RNase so it could be the natural physiological electron donor of the TPx protein [4]. It participates in the electron transfer pathway through the reversible oxidation of two neighboring cysteines in a biochemical cycle that involves TRX reductase and NADPH $[8,9]$. Finally, Thioredoxin glutathione reductase, considered as a "general disulfide reductase" is involved in the reduction of exposed disulfide bonds of a variety of proteins and thus the entire system is able to metabolize $\mathrm{H}_{2} \mathrm{O}_{2}$ and other alkyl peroxides [10]. With this protein the antioxidant system of 
detoxification of the parasite is completed whose proposed model is as follows: TPx protects against ROS inactivation in an oxidation system catalyzed by Fe3 + using thiol and / or ascorbate.

\section{Conclusion}

The reducing agent is responsible for activating the enzyme by reducing disulfide bridges. Oxidized sulfhydryl groups are regenerated by transferring reducing agents from NADPH to thioredoxin reductase, from it to thioredoxin and finally to TPx as shown in the (Figure 3) [4]. It does not seem logical to think that NAPH acts extracellularly as a source of the necessary reducing power. Therefore, the theory of acting inside the cell is postulated, so that proteins could be secreted in a reduced state. Thus, the parasite defense system against ROS products (reactive oxygen species) generated by the host's immune response and by the parasite's own metabolism is described.

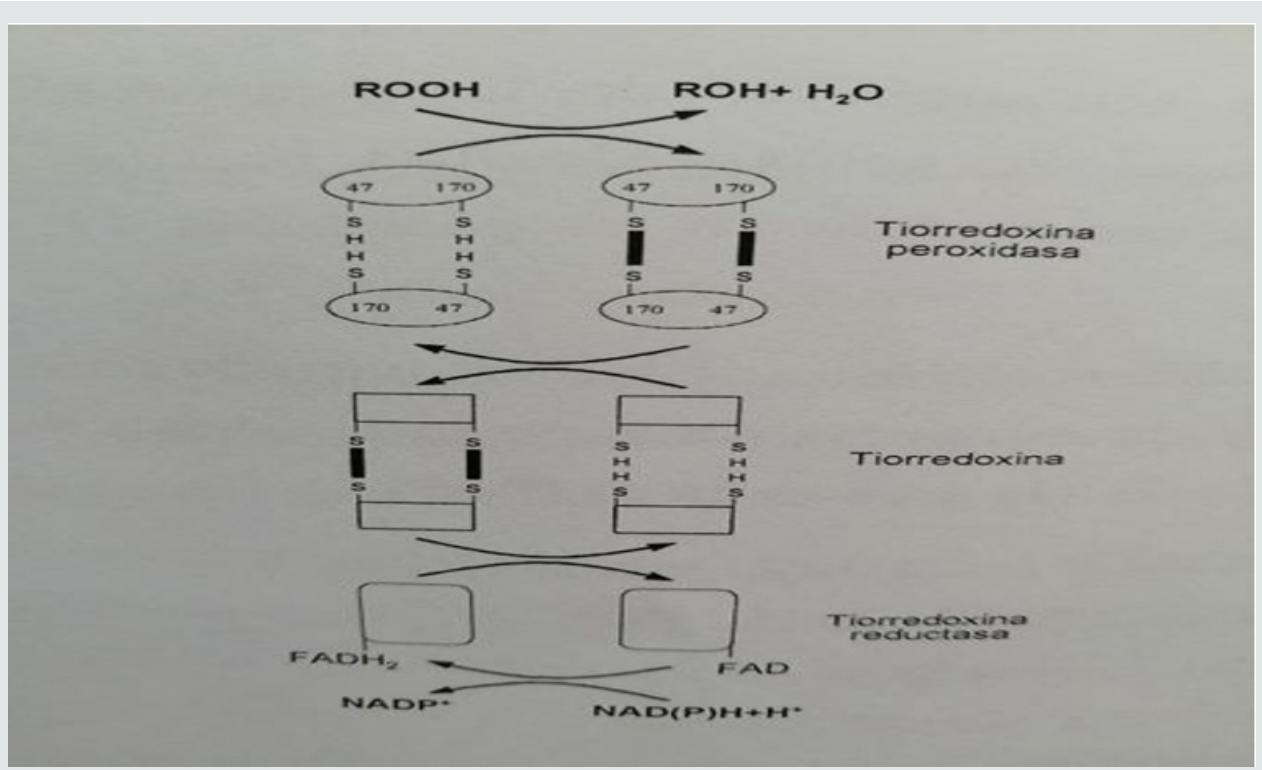

Figure 3: Mechanism of action of the antioxidant protein system of the Excretory System - Fasciola hepatica secretor.

\section{References}

1. Piacenza Bengochea, María Lucía (1996) Sistemas antioxidantes en helmintos parásitos pp: 500-577.

2. Chiumiento, Lorena, Fabrizio Bruschi (2009) Enzymatic antioxidant systems in helminth parasites. Parasitology Research 105(3): 593-603.

3. Maggioli, Gabriela (2004) Purification, characterization, and immunolocalization of a thioredoxin reductase from adult Fasciola hepatica. Journal of Parasitology 90(2): 205-212.

4. Salazar Calderon M Elisa (2000) Identificación y caracterización funcional de proteínas antioxidantes en el extracto excretor-secretor de fasciola hepatica (Doctoral dissertation, Universidad de Oviedo).

5. Salazar Calderón M, Martín Alonso JM, De Eguino ADR, Casais R, Marin MS, et al. (2000) Fasciola hepatica: heterologous expression and functional characterization of a thioredoxin peroxidase. Experimental parasitology 95(1): 63-70.
6. Salazar Calderón M, Martín Alonso JM, De Equion ADR, Parra F (2001) Heterologous expression and functional characterization of thioredoxin from Fasciola hepatica. Parasitology research 87(5): 390-395.

7. Paz M (2016) Expression, purifications y caracterización de peroxiredoxins recombinants de Fasciola hepática y humanas: Clonado direccional de los genes codificantes para las triparredoxina peroxidasas de Trypanosoma cruzi. Tessina, Universidad de Uruguay, South America.

8. Line K, Isupov MN, Garcia Rodriguez E, Maggioli G, Parra F, et al. (2008) The Fasciola hepatica thioredoxin: High resolution structure reveals two oxidation states. Molecular and biochemical parasitology 161(1): 44-48.

9. Gretes MC, Poole LB, Karplus PA (2012) Peroxiredoxins in parasites. Antioxidants \& redox signaling 17(4): 608-633.

10. Cuinat, Gabriela Maggioli (2007) Identificacion and caracterizacion de una tiorredoxina glutation reductasa de fasciola hepatica. Diss. Universidad de Oviedo. 
(C) (i) This work is licensed under Creative

To Submit Your Article Click Here: $\quad$ Submit Article

DOI: $10.32474 /$ LOJPCR.2019.01.000123

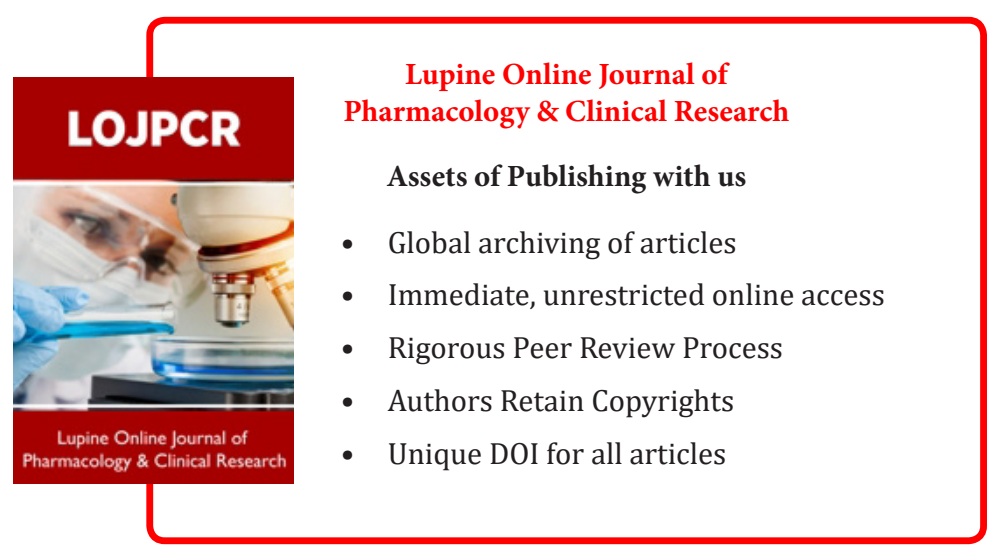

